\title{
The influence of a digital strategy on the digitalization of new ventures: The mediating effect of digital capabilities and a digital culture
}

\author{
Dorian Prokscha, , Anna Frieda Rosinc, Stephan Stubner ${ }^{c}$, and Andreas Pinkwart ${ }^{\mathrm{a}}$ \\ aStiftungsfond Deutsche Bank Chair of Innovation Management and Entrepreneurship, HHL Leipzig

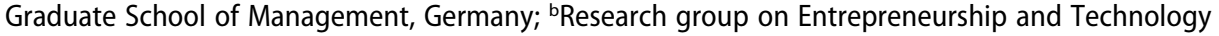 \\ Management (ETM), Faculty of Behavioural, Management \& Social Studies, University of Twente, The \\ Netherlands; 'Dr. Ing. h.c. F. Porsche AG Chair of Strategic Management and Digital Entrepreneurship, \\ HHL Leipzig Graduate School of Management, Germany
}

\begin{abstract}
A higher degree of digitalization in new ventures' product/ service offerings and their processes can lead to a faster time to market and the ability to rapidly scale. Hence, it has the possibility to significantly impact the performance. To increase the degree of digitalization in new ventures, they can implement a digital strategy. Currently there is no evidence if this measure has a strong impact on the degree of digitalization. We therefore empirically investigate the influence of a digital strategy on the degree of digitalization in new ventures' products/ services and processes. We analyzed 102 new ventures using SEM. Building on the contingency theory, we show that only having a digital strategy is insufficient to achieve a high degree of digitalization. The digitalization of products/services is partially mediated by digital IT capabilities, and the effect of digital strategy on process digitalization is partially mediated by digital IT capabilities and a digital culture.
\end{abstract}

\section{KEYWORDS}

Digital entrepreneurship; digital new ventures; digital strategy

\section{Introduction}

Today up to 90 percent of new ventures fail, while a big portion can be traced back to strategic failures in assigning scare resources (Davidsson et al., 2017; Steininger, 2019). Choosing the right strategic orientation to decide how to create value-adding products/services and to carry out optimal processes is therefore imperative for new ventures' survival (N. Kim et al., 2013; Srinivasan et al., 2002; Zhou et al., 2005). Recent research findings point toward an increasing importance of digitalization as part of a firm's strategic orientation to be competitive (N. Kim et al., 2013; Sirmon et al., 2010). Digitalization, which describes the usage of digital technologies in digital products/services as well as digital processes, among others, is assigned a variety of benefits. These, for example, encompass an increase in development speed and launching

CONTACT Dorian Proksch d.e.proksch@utwente.nl Faculty of Behavioural, Management \& Social Studies, RA2109, P.O.Box 217, Enschede 7500 AE, The Netherlands.

(- Supplemental data for this article can be accessed on the publisher's website. 
speed of new products, increasing new ventures' flexibility, a possible faster internationalization, as well as saving tangible and intangible resources (Moreno-Moya \& Munuera-Aleman, 2016; Nambisan, 2017; Pergelova et al., 2019). More specifically a higher degree of digitalization in new ventures enables firms to be successful with regard to, for example, generating higher customer satisfaction and loyalty through flexible adaptation of the digital product/service offering according to a customer's needs or by increasing the operational efficiency through digital processes (Autio, 2017; Rachinger et al., 2018).

Thus, the strategic orientation on increasing the degree of digitalization in new ventures products/services and processes can help those firms to better manage their scarce resources (Nambisan, 2017). To capitalize on the benefits of these current developments, many firms have incorporated a digital strategy (Sebastian et al., 2017). In the corporate literature, a digital strategy has been found to derive benefits in terms of the development of digital products/ services and processes (Bharadwaj et al., 2013; Sebastian et al., 2017).

It is thus surprising that the current entrepreneurship literature lacks empirical investigations of the influence of a digital strategy on increasing the degree of digitalization in new ventures products/services and processes. This topic has gained some attention in related areas in the field of small and medium-sized enterprises (SMEs) (Bi, Davison, \& Smyrnios, 2019; Eggers et al., 2017; S.H. Kim et al., 2017; Moreno-Moya \& Munuera-Aleman, 2016; Mohd Salleh et al., 2017; Nguyen et al., 2015; Pergelova et al., 2019); however, we argue that the results may not apply for new ventures due to the resource constraints and the liabilities of smallness. First advancements in the field of entrepreneurship focus on the IT rather than the digitalization aspect (GarcíaCabrera et al., 2019; Parida \& Örtqvist, 2015; Tornikoski et al., 2017).

We therefore answer the research question of whether a digital strategy can increase the degree of digitalization of new ventures' digital products/services and digital processes. This might possibly enable a fast scaling of the company and therefore a superior performance (Pergelova et al., 2019). We analyzed 102 new German ventures using structural equation modeling (SEM) in the form of a partial least squares (PLS) approach.

Investigating the influence of a digital strategy on the degree of new ventures' digital products/services is important because of three main reasons. First, it answers current calls for research to study the role of strategy as well as the usage of digital technologies in the entrepreneurial context (Berger et al., 2018; Ott et al., 2017). Second, knowing how to leverage a digital strategy to create more digital products and services can help new ventures to create additional value for customers (Amit \& Zott, 2001; Rachinger et al., 2018). Third, understanding the influence of a digital strategy on the degree of digitalization in terms of processes supports new ventures in identifying potential for increased flexibility and efficiency in their operations, which 
can result in cost advantages (Amit \& Zott, 2001; Nambisan, 2017). Consequently, increasing the degree of digitalization in products/services as well as processes of new ventures with the help of a digital strategy might be a viable measure for new ventures to develop competitive advantages and thus be able to survive in the long run (Rachinger et al., 2018; Steininger, 2019).

The remainder of this article is structured as follows. In the next section, we introduce our theoretical framework, which investigates the influence of a digital strategy on digital products/services as well as digital processes of new ventures. We further introduce our hypotheses to test for potential mediators in this relationship. Then we describe the methodology of our empirical study and present and discuss the results. Finally, we highlight the implications and present the limitations.

\section{Theory and hypotheses}

\section{Digital strategy and degree of digitalization}

How a new venture defines its structures, processes, and initiatives is a result of its strategic orientation (Kickul \& Walters, 2002). A firm's strategy is the overall direction or vision set by the management for the firm's upcoming years. As a result, the success of a new venture depends on strategic decisions by the management on how to allocate resources as well as which capabilities to develop. According to Schuler and Jackson (1987), there are three types of strategy: innovation, cost, and quality. We focus on the innovation strategic orientation, which includes a focus on digitalization. New ventures following an innovation strategic orientation are typically tolerant of risk and open to change. As a result, those new ventures are often the first to identify new opportunities, for example, with the help of digital technologies. Due to the increasing incorporation of digital technologies in firms' products as well as rising customer demand with regard to the availability of digital services, digitalization can hardly be separated from new ventures' strategy nowadays (Bharadwaj et al., 2013; El Sawy, 2003). Moreover, the growing usage of digital technologies gives rise to new business opportunities, which help firms to digitalize processes and enable increased efficiency. To capitalize on the benefits of these current developments, many established firms have incorporated a digital strategy (Sebastian et al., 2017).

A digital strategy can be conceptualized as an organizational strategy that leverages digital resources to generate differential value (Bharadwaj et al., 2013). Consequently, Sebastian et al. (2017, p. 198) define it as "a business strategy, inspired by the capabilities of powerful, readily accessible technologies [...], intent on delivering unique, integrated business capabilities in ways that are responsive to constantly changing market conditions." This overarching definition is different from related concepts, such as an IT strategy, 
which only focus on the functional level in an organization and act as enablers of a particular business strategy. For firms that aim to be a successful part of the digital era, a digital strategy is one of the most relevant resources to incorporate digitalization in firms (N. Kim et al., 2013).

Digitalization describes "the application of digital technologies and infrastructures in business, economy, and society" (Autio, 2017, p. 1). It therefore includes the concept of digitization, which is the process of transferring data and information from an analog format to a digital format (Bleicher \& Stanley, 2019).

The more a firm has incorporated digitalization, the higher the degree of digitalization. We define the degree of digitalization similar to Hull et al.'s (2007) conceptualization, distinguishing between different degrees of digitalization by means of increasing involvement of digital products/services and digital processes. A new venture without any degree of digitalization is offering a nondigital product/service and utilizes manual processes; a new venture with a low degree of digitalization refers to digital products/services and digital processes as a supplement to traditional offerings. With an increasing degree of digitalization, a new venture is putting a higher focus on digital products/ services and processes. A high degree of digitalization thus refers to a new venture that is entirely digital-including the complete product and service offering along with any possible processes (Hull et al. 2007).

\section{Digital products/services and digital processes of new ventures}

In the entrepreneurship literature, digitalization appears mainly in terms of digital products/services offered by new ventures and incorporated digital processes (Hull et al. 2007; Nambisan, 2017; Rachinger et al., 2018). Digital products/services of new ventures are defined as products and services that are made possible or enabled through digital technologies (Lyytinen et al., 2016; Porter \& Heppelmann, 2014). In this regard, not only entirely new products but also digitally enhanced consumer products and add-on digital tools belong in this category (Hull et al. 2007; Lyytinen et al., 2016). Digital products/services can include any kind of digital element, media usage, or application as well as digital components that provide the product or service's main functionality (Kallinikos et al., 2013; Nambisan, 2017). The entrepreneurship literature notes that the digitalization of products/services has a significant influence on the value creation of new ventures (Rachinger et al., 2018).

Digital processes are all activities that create value by means of digital technologies (BarNir et al., 2003; Kannan \& Li, 2017). They provide digital architectures to create complementary offerings (Nambisan, 2017). Thus, digital processes include, for example, digital interaction with different stakeholders, digital distribution, digital operations, or digital marketing (Hull et al. 
2007). Digital processes are not limited to one specific part of the value chain; they can be applied along the entire chain (Bogner et al., 2016).

\section{Influence of a digital strategy on digitalization of products/services and processes}

The extant literature has already highlighted digitalization as an important part of the strategic orientation of firms (Im \& Workman, 2004; Zhou et al., 2005). N. Kim et al. (2013) even emphasized that a digital strategy is one of the most relevant aspects in incorporating digitalization in firms.

To investigate the influence of a digital strategy on the degree of digitalization in terms of digital products/services and digital processes of new ventures and thus improving the performance in the domains of digitalization, we refer to the contingency theory. The theory emphasizes the importance of a firm's management to transform resources into capabilities to improve organizational performance (Symeonidou \& Nicolaou, 2018; Venkatraman \& Camillus, 1984). There is not a single best way that leads to organizational success, but a variety of internal and external contingencies have to be taken into account (Shepard \& Hougland, 1978). The theory is preferred in strategy analysis over the resource-based view with respect to the alignment of resources and strategy relationships as well as valueadding capabilities (Chirico et al., 2011; Gruber et al., 2010; Sirmon et al., 2010).

Applied to the field of digital strategy, the theory enables us to investigate the alignment of interorganizational factors to improve digital performance in two domains of new ventures: digital products/services and digital processes. Thus, a digital strategy set by the management of new ventures helps to align multiple organizational factors to increase the degree of digitalization in terms of digital products/services and digital processes (Symeonidou \& Nicolaou, 2018; Venkatraman \& Camillus, 1984). In our study, we focus on firm-level capabilities.

Established firms that incorporate a digital strategy have been found to benefit from (a) enhanced digital products/services or developing completely new ones (Sebastian et al., 2017), and (b) improving internal work routines by developing digital processes (Bharadwaj et al., 2013; McConnell, 2015). We believe that the incorporation of digitalization in a firm's business strategy is especially relevant in the field of entrepreneurship. In recent entrepreneurial business models, the digitalization of products/services and processes can barely be separated from new ventures' overall strategy (Bharadwaj et al., 2013). Thus, we believe that incorporating a digital strategy in new ventures should have an effect on the digitalization of those firms in terms of digital products/services and digital processes too. This holds especially true because new ventures are typically smaller and younger than established corporations, 
resulting in the fact that a strategy provided by the founders should be more easily adoptable (Kearney et al., 2019). We therefore hypothesize:

Hypothesis 1a: A digital strategy positively affects the degree of digitalization in new ventures' digital products/services.

Hypothesis 1b: A digital strategy positively affects the degree of digitalization in new ventures' digital processes.

Current research is not only referring to digital strategy as a means to influence the degree of digitalization in new ventures ' products/services and processes but also describing three intervening factors. Those factors include digital information technology capabilities (BarNir et al., 2003), employees' digital capabilities (Prokesch, 2017), and a digital culture (Deuze, 2006). Dynamic capabilities, which can be defined as the ability to develop internal competence, are required to follow the strategic orientation to incorporate digitalization in new ventures (Teece, 2007). This follows the contingency theory, which emphasizes that factors such as the organizational structure, the employees, and the infrastructure of the firm have to be taken into account for a good managerial outcome (Shepard \& Hougland, 1978).

\section{Mediating role of digital IT capabilities}

Digital IT capabilities have been found to influence the degree of digitalization in firms (BarNir et al., 2003; Neus et al., 2017; Souza et al., 2017). DeLone et al. (2018) define digital IT capabilities as the ability to use technological applications to create value for customers, suppliers, and the firm itself. Those technical applications include software and hardware. They form the basis to develop digital products/services. We therefore assume that digital IT capabilities support a digital strategy in increasing the degree of digitalization of new ventures' products/services (Denner et al., 2018). Having digital IT capabilities allows firms to collect customer feedback through digital platforms to actively integrate customers' opinions within the progress of digitalizing products/ services. As such, digital IT capabilities might be also supportive in enabling more rapid digital innovation that comes alive in digital products/services (DeLone et al., 2018; Von Briel et al., 2018). Furthermore, we suppose that the effect of digital strategy on digital processes is strengthened by digital IT capabilities as new ventures need suitable digital IT capabilities to automate their processes (Berghaus et al., 2017; Souza et al., 2017). Digital IT capabilities enable new ventures to connect their IT with digital offerings, such as digital payment, logistics, and customer- or supplier-relationship management systems, which can lead to more flexible digital relations between a firm's internal and external resources and processes. Considering these positive effects of digital IT capabilities, we assume a mediating effect of digital IT capabilities on 
the relationship between a digital strategy and digital products/services as well as digital processes. Consequently, we hypothesize:

Hypothesis 2a: The relationship between digital strategy and digital products/services is mediated by the digital IT capabilities.

Hypothesis 2b: The relationship between digital strategy and digital processes is mediated by the digital IT capabilities.

\section{Mediating role of employees' digital capabilities}

In addition to the importance of a digital strategy, various researchers highlight the significance of employees' digital capabilities for new ventures' digitalization (Parida et al., 2015; Prokesch, 2017). Employees' digital capabilities reflect team members' ability to make use of digital technologies (Arkhipova \& Bozzoli, 2018), resulting from digital experience and technical know-how (Bassellier et al., 2001). For example, to make use of big data analytics, team members must be familiar with applications that allow them to store, process, and use a large volume of data to simulate scenarios, create networks, or build causal explanations (Arkhipova \& Bozzoli, 2018). The results of such work can, for instance, be used to improve or to create innovative new digital products/services or processes (Ritter \& Gemünden, 2004).

We therefore assume a mediating effect of employees' digital capabilities on the effect of a digital strategy on the digitalization of new ventures. Employees' digital capabilities include, for example, the ability to actively exchange information and documents through digital platforms, such as cloud services (Fischer \& Reuber, 2014), as well as the capabilities to use digital channels (including mobile and social media) to integrate digital communication processes (BarNir et al., 2003). Thus, employees' digital capabilities might reinforce the effect of a digital strategy in terms of digital products/services and processes. Having a high degree of digital capabilities enables employees to track processes in real time so that workflows become more transparent. This allows for identification of processes that can be digitally improved or enhanced (Iivari et al., 2016; Knight \& Cavusgil, 2004). Thus, we anticipate a mediating effect of employees' digital capabilities between a digital strategy and the digitalization of new ventures' products/services and processes (Nylen \& Holmström, 2015). Therefore, we hypothesize:

Hypothesis 3a: The relationship between digital strategy and digital products/services is mediated by employees' digital capabilities.

Hypothesis 3b: The relationship between digital strategy and digital processes is mediated by employees' digital capabilities. 


\section{Mediating role of digital culture}

The extant research emphasized the significant role of a company's digital culture in tapping the full potential of the digitalization in new ventures (Deuze, 2006; Nylen \& Holmström, 2015; El Sawy et al., 2016). A digital culture is defined as "an emerging set of values, practices and expectations regarding the way people (should) act and interact within the contemporary network society" (Deuze, 2006, p. 1). A new venture's culture encompasses common behavioral rules that determine its identity (Punnett \& Ricks, 1990).

We assume that a digital culture might enhance the effect of a digital strategy on the degree of digitalization in products/services and processes of new ventures as it helps to unfold the potential of a digital strategy. A digital culture also allows for flat hierarchies and decentralized decision-making, which provide room for creativity and thereby creating opportunities for the development of digital products/services (McConnell, 2015; Nylen \& Holmström, 2015). A digital culture generates new knowledge and increases inventiveness, thereby supporting the development of new products/services (Duerr et al., 2018). In addition, a digital culture leads to changes in the firm's behavior arising from the use of technology. This culture might include agile and flexible working styles; a digital-first mindset; an adaptive skill set that allows for failure when establishing digital abilities; and a focus on data, which might influence the degree of the digital processes in new ventures (El Sawy et al., 2016). Thus, we believe that a digital culture could mediate the relationship of a digital strategy and digital products/services as well as digital processes in new ventures, as it creates an environment in which team members are empowered to make use of digital technologies (Deuze, 2006). This leads us to hypothesize:

Hypothesis 4a: The relationship between digital strategy and digital products/services is mediated by digital culture.

Hypothesis 4b: The relationship between digital strategy and digital processes is mediated by digital culture.

Figure 1 summarizes our theoretical framework.

\section{Methodology}

\section{Data}

Our study focuses on new German ventures. We define a new venture in this article as an organization that was established within the past 10 years and offers an innovative product, service, or business model (Candi \& Saemundsson, 2008; Zahra, 1995). Focusing on new ventures in Germany while studying the digitalization of new ventures is important for several 


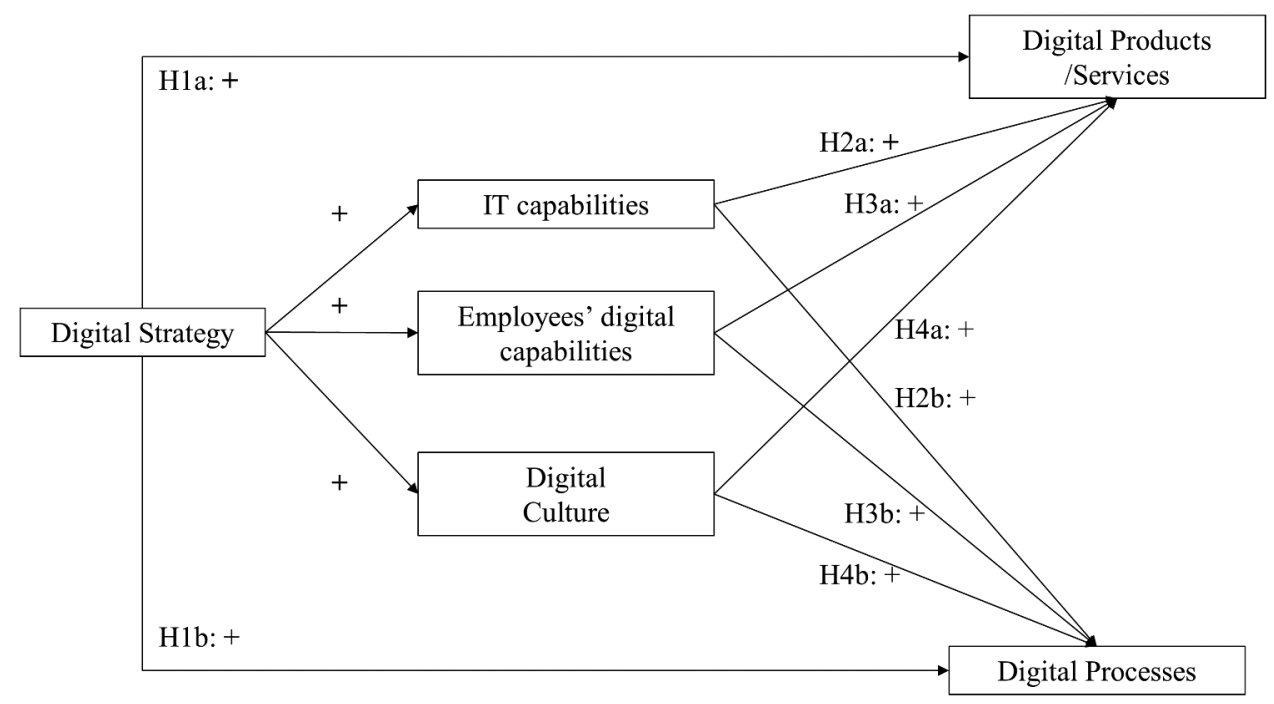

Figure 1. Theoretical framework.

reasons. First, the capital of Germany, Berlin, is often ranked as one of the most important cities for founders in the field of digitalization-for example, seventh place globally in Startup Genome's "2017 Global Startup Ecosystem Report" (Startup Genome, 2017) and fourth place globally in Nestpick's "Startup City Index" (Nestpick, 2017) - which demonstrates the global relevance of the German entrepreneurial ecosystem. Second, new ventures in Germany receive 29 percent of Europe's venture-capital investments, which highlights the important role of new German ventures for European investors (KPMG, 2018).

We collected our data through an open-source online survey tool (LimeSurvey) from May 2018 until November 2018 using a snowballing sampling technique. We chose this technique because the true population of new digital ventures in Germany is unknown. Snowballing is an effective method to build a homogeneous sample for hard-to-reach populations (Khelil, 2016; Neergaard, 2007). Furthermore, snowball sampling is a common approach in entrepreneurship research (Fischer \& Reuber, 2014; Gruber et al., 2015; Kuhn \& Galloway, 2015).

For the data collection we recruited participants at two entrepreneurship conferences and shared the survey link with entrepreneurs within a university network whose private business school had many alumni who had started digital businesses. Thus, these were effective methods to acquire respondents for our survey. We asked respondents to refer us to other potential participants. We explicitly did not focus on a particular industry because we used a multiconstruct approach to measure digitalization; for example, a software company might offer only digital products/services but might not have 
digitalized the processes internally, and a pharmaceutical company might offer a nondigital product but have a high degree of digitalization of internal processes.

In total, we collected 116 responses. We stopped the collection period when subsequent respondents began referring us to founders who already participated in our survey. In the end, we removed responses from 14 organizations from our final calculation, 10 of which were not headquartered in Germany and four of which were older than 10 years. Therefore, our final model contains 102 cases. With regard to position in the organization, 70.6 percent of the respondents were members of the founding team, 15.7 percent were members of the management team, and 13.7 percent were employees. The majority of the respondents were aged 25-34 years (59.8 percent) and 35-44 years (24.5 percent); nine respondents were older, and seven were younger. Most of the respondents had a business/economics background (61 participants), 11 had an IT background, four an engineering background, six a life science background, eight a social science background, one a law background, and 11 respondents had other backgrounds. We established a balanced data set in the sense of snowball sampling: On the selfassessment of how digital the company is on a Likert scale from 1 (not digital at all) to 5 (completely digital), 45 participants responded with 4 , which is also the median; the average is 3.9. Thirty-one respondents selected 5, and 26 respondents chose less than 4 . This variation shows that the degree of digitalization of the ventures is high within our data set, still keeping enough variance for statistical analysis.

To establish a high reliability in creating our model, we conducted an approach adapted from Davidsson et al. (2017). First, the four authors of our article refined the items identified in literature. We had two experts in the author's team: One of the authors is a successful digital entrepreneur and a frequent investor in digital businesses, and one of the authors is Minister of Economic Affairs, Innovation, Digitalization and Energy of the State of North Rhine-Westphalia, Germany. Then we discussed the survey questions with four researchers in the field outside the author team and adapted the questions based on their feedback. Thereby, we focused especially on improving the understandability of the questions and items. In the next step, we conducted two pretests involving a total of 17 participants in which we asked the participants specifically to provide feedback to the survey questions; we adapted our survey accordingly. This process identified several items that were more appropriate for established firms than for new ventures. We iteratively changed the respective items. Further, we looked for outliers in our constructs that might have been caused by misunderstanding and refined these items accordingly.

After the two pretests, we conducted a pilot study with 24 participants in which we specifically looked for the reliability of the constructs and for 
significant items. At this point, the constructs exhibited high reliability; therefore, we decided to start the final data collection. The participants of the two pretests and the pilot study were excluded from the final data collection.

On average, the new ventures of our final data set were 3.4 years old (median: 3). Sixteen companies were in the idea or pre-seed round, 38 were in the seed round, 27 were in a later financing round, 18 companies were in the expansion stage, and three were in the exit phase. The industry distribution was diverse, with participating organizations active in IT/consumer electronics (12 participants), consumer services (11 participants), and consumer commerce (nine participants), among others. Seventy-five out of the 102 new ventures had at least one founder with a technical background in the team.

\section{Method}

We used variance-based structural equation modeling (SEM) to build and test our model. As the digital strategy, the mediators, and the degree of digitalization for products/services as well as processes cannot be measured directly, we created constructs that included several items. We used SEM in the form of partial least squares (PLS), which has recently gained popularity in entrepreneurship, strategic management, and general management research (Hair et al., 2012b; Kuckertz \& Prochotta, 2018). A PLS model consists of an outer model that includes the constructs and their items and an inner model that includes the constructs and their relations. We estimated the model parameters in three steps (Henseler et al., 2009). First, the algorithm iteratively estimates the latent variable score (the score for each construct). Second, the algorithm estimates the outer weights/loadings and path coefficients (using multivariate linear regression to estimate the latter). Third, the algorithm determines the location parameters. See Hair et al. (2016) and Sarstedt et al. (2016) for a detailed description of the PLS method and its usage.

We had different reasons for choosing PLS. First, PLS is an effective method for explorative research aimed at creating new theories (Hair et al., 2016). Our research can be considered explorative because models that measure the degree of digitalization of new ventures are currently missing in entrepreneurship research. Second, PLS models are desirable when the research goal is to explain the variance of the model (Hair et al., 2012a). In studying the influence of a digital strategy as well as other factors that might have an effect on the degree of digitalization in terms of products/services and processes of new ventures, we tried to maximize the explained variance.

We calculated our model using SmartPLS software (version 3.2.7; Ringle et al., 2015) using the default properties that include a path weighting scheme, 300 maximum iterations, a stop criterion of $10^{-7}$, and initial outer weights of +1 . We used a reflective measurement mode for all our constructs. An 
explanation for this choice can be found in Online Appendix E. For the mediation analysis, we followed the recommendations of Nitzl et al. (2016) and Hayes (2017).

\section{Measures}

We based our constructs on items identified in the literature. Table 1 lists all the items as well as the survey questions. We used 5-point Likert scales for all items.

We measured the digital strategy using five items, which we adapted from the technology orientation literature (Chen et al., 2014; Hakala \& Kohtamäki, 2011; N. Kim et al., 2013). The original construct measures the technology orientation with the company's strategy, and we tailored it to the field of digitalization and updated one item after the pretest.

To measure digital IT capabilities, we used seven items. The original construct was based on an adaptation of items measuring information and communication technology capabilities (Chen et al., 2015; Parida \& Örtqvist, 2015; Wales et al., 2013) and digital platform capabilities (Cenamor et al., 2019). We adapted the items during the pretests to fit the context of new ventures.

We measured employees' digital capabilities using five items. The original construct was based on an adaptation of items from the technological competence and expertise construct (Knight \& Cavusgil, 2004; Ritter \& Gemünden, 2004) as well as the IT competencies construct and its adoptions (Bassellier et al., 2001). We updated the items during the pretest to tailor them to the unique human resources conditions in new ventures.

We measured digital culture using five items based on the construct of adhocracy culture by Lukas et al. (2013) and the findings of Duerr et al. (2018), although we included only items applicable to new ventures. We updated the items during the pretest to adapt them to the culture of new ventures.

We measured the digitalization of the product and services relying on the constructs of innovation implementation (McAdam et al., 2010), technological innovation (Tang \& Murphy, 2012), and innovation radicalness (Marvel \& Lumpkin, 2007). We extensively updated the items after the pretest.

We initially measured digitalization of processes using items from the constructs of business process digitization (BarNir et al., 2003; Bengtsson et al., 2007), new process creativity (Rindfleisch \& Moorman, 2001), and the findings of Markus and Loebbecke (2013). However, we strongly revised the construct according to pretest feedback.

\section{Control variables}

We included several control variables in our study. First, we included the age of the new venture as a control, as it is one of the most common control 


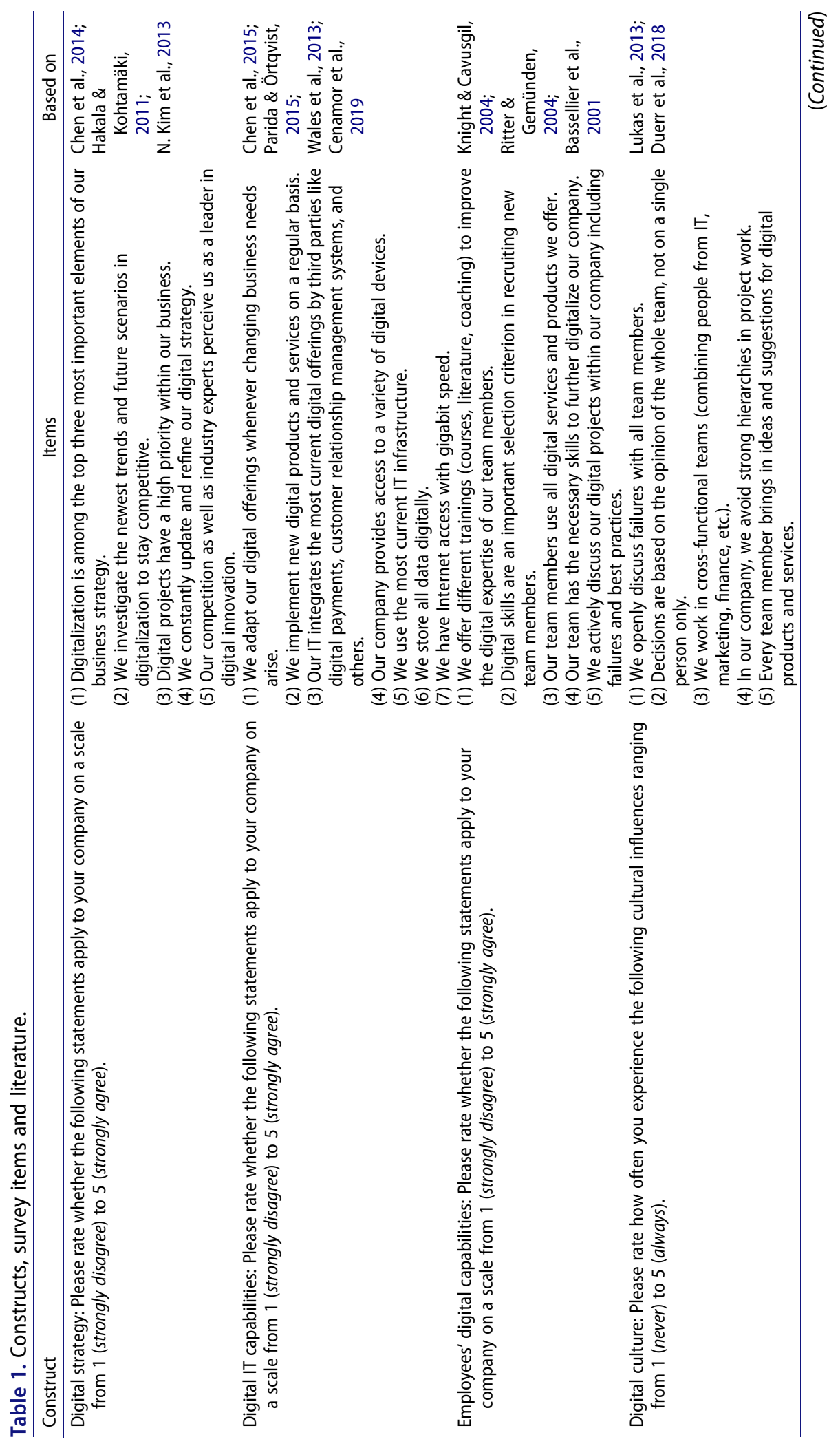




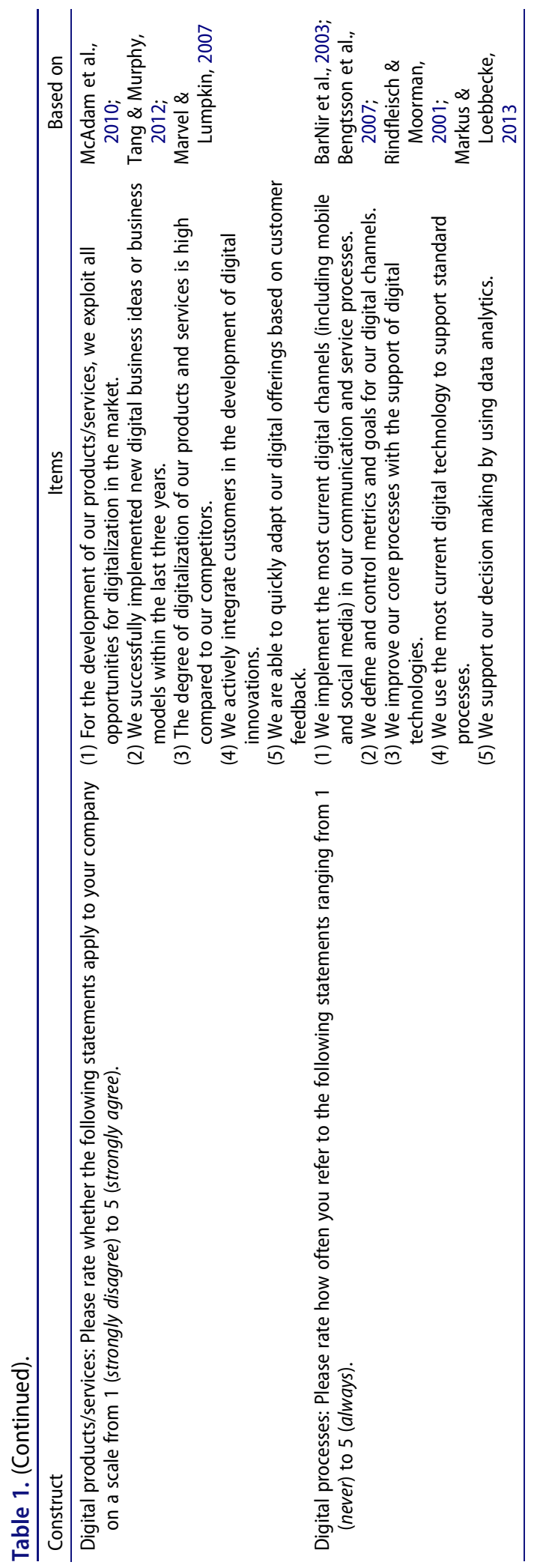


variables in entrepreneurship and digitalization research (see BarNir et al., 2003; Sarangee \& Echambadi, 2014). Second, we included the investment round because in a later stage, scaling the business is typically a high priority. For scaling purposes, digitalization might become more important. Third, participants were asked to specify the new venture's industry. A new venture active in the field of IT might be more inclined to adopt digital technologies than a new venture in, for instance, the drug development field.

\section{Results}

We first assessed the validity of our constructs. We iteratively removed items with loadings of less than 0.7 following Hair et al.'s (2016) guidelines. We removed one item from the digital IT capabilities construct, two from the employees' digital capabilities construct, and one from the digital culture construct. We reached the threshold for composite reliability and average variance extracted (AVE). In addition, we removed two items from the digital IT capabilities construct, one from the digital process construct, and two items from the digital strategy construct to increase the discriminant validity. We did not remove any items from the digital products/services. Table 2 shows the loadings and $p$ values of the remaining items based on 5,000 bootstrapping rounds. All of our items had 99.9 percent significance. The descriptive

Table 2. Factor loadings and $p$ values of the used items in our model.

\begin{tabular}{|c|c|c|c|c|c|c|}
\hline Item & $\begin{array}{l}\text { Digital } \\
\text { strategy }\end{array}$ & $\begin{array}{c}\text { Digital IT } \\
\text { capabilities }\end{array}$ & $\begin{array}{l}\text { Employees' digital } \\
\text { capabilities }\end{array}$ & $\begin{array}{l}\text { Digital } \\
\text { culture }\end{array}$ & $\begin{array}{c}\text { Digital pro- } \\
\text { ducts/services }\end{array}$ & $\begin{array}{l}\text { Digital } \\
\text { processes }\end{array}$ \\
\hline Strategy 1 & $0.852^{* * *}$ & & & & & \\
\hline Strategy 3 & $0.909^{* * *}$ & & & & & \\
\hline Strategy 4 & $0.903^{* * *}$ & & & & & \\
\hline IT 1 & & $0.773^{* * *}$ & & & & \\
\hline IT 3 & & $0.822^{* * *}$ & & & & \\
\hline IT 4 & & $0.819^{* * *}$ & & & & \\
\hline Employee 2 & & & $0.833^{* * *}$ & & & \\
\hline Employee 4 & & & $0.818^{* * *}$ & & & \\
\hline Employee 5 & & & $0.849^{* * *}$ & & & \\
\hline Culture 1 & & & & $0.724^{* * *}$ & & \\
\hline Culture 2 & & & & $0.594^{* * *}$ & & \\
\hline Culture 3 & & & & $0.786^{* * *}$ & & \\
\hline Culture 5 & & & & $0.787^{* * *}$ & & \\
\hline Product/Serv. 1 & & & & & $0.865^{* * *}$ & \\
\hline Product/Serv. 2 & & & & & $0.734^{* * *}$ & \\
\hline Product/Serv. 3 & & & & & $0.823^{* * *}$ & \\
\hline Product/Serv. 4 & & & & & $0.782^{* * *}$ & \\
\hline Product/Serv. 5 & & & & & $0.790^{* * *}$ & \\
\hline Processes 2 & & & & & & $0.762^{* * *}$ \\
\hline Processes 3 & & & & & & $0.905^{* * *}$ \\
\hline Processes 4 & & & & & & $0.847^{* * *}$ \\
\hline Processes 5 & & & & & & $0.821^{* * *}$ \\
\hline
\end{tabular}

Note. Unstandardized $\beta \mathrm{s}$.

$+p<.10,{ }^{*} p<.05,{ }^{* *} p<.01,{ }^{* * *} p<.001$. 
statistics for the items as well as a correlation table are available in the Online Appendix A.

In addition, we assessed the reliability of our constructs using Cronbach's alpha, composite reliability, and the AVE (see Table 3 for results). We used a threshold of 0.7 for Cronbach's alpha (Hair et al., 2016), and all of our constructs exceeded this value. In addition, all constructs exceeded the composite reliability threshold of 0.7 as well as the AVE threshold of 0.5 (Hair et al., 2016). We conclude that, in general, our constructs are reliable.

To assess discriminant validity, we adopted the Fornell-Larcker criterion and the cross-loading approach. Both confirm discriminant validity (see Online Appendices OA.B1 and OA.B2). In addition, we used the heterotraitmonorait ratio (HTMT). We used the threshold of 0.8 (Hair et al., 2016, p. 119). Our model also passed this test (see Online Appendix OA.B3).

Table 4 shows the path coefficients, effect sizes, and the explained variance for our model. The explained variance is high for the products or services and the processes constructs, as the first exceeds the 0.5 threshold and the second is only slight below that (Hair et al., 2016).

First, we tested whether digital strategy relates to the degree of digitalization of product and services. The effect of digital strategy is strong (beta of 0.360 ) and significant $(p<.001)$, therefore supporting H1a. When we include digital IT capabilities, employees' digital capabilities, and digital culture in the model, digital strategy and digital IT capabilities are significant, but employees' digital capabilities and digital culture are not. Therefore, the digital strategy is partially mediated by digital IT capabilities. We can confirm $\mathrm{H} 2 \mathrm{a}$, but we must reject $\mathrm{H} 3 \mathrm{a}$ and $\mathrm{H} 4 \mathrm{a}$. Furthermore, the explained variance is above 50 percent, indicating that the degree of digital products/services is well explained by the digital strategy and digital IT capabilities.

Second, we tested whether digital strategy explains the degree of the digitalization of the new ventures' processes. The effect of digital strategy is strong (beta of 0.244 ) and significant $(p<.05)$, therefore supporting H1b. When we included digital IT capabilities, employees' digital capabilities, and digital culture in the model, we found that digital strategy, digital IT capabilities, and digital culture are significant. We conclude that digital strategy is partially mediated by these three variables. We therefore can accept $\mathrm{H} 2 \mathrm{~b}$

Table 3. Reliability criteria for the constructs.

\begin{tabular}{lccc}
\hline Construct & Cronbach's alpha & Composite reliability & AVE \\
\hline Digital strategy & 0.867 & 0.918 & 0.789 \\
Digital IT capabilities & 0.729 & 0.847 & 0.648 \\
Employees' digital capabilities & 0.781 & 0.872 & 0.695 \\
Digital culture & 0.715 & 0.816 & 0.528 \\
Digital products/services & 0.859 & 0.899 & 0.641 \\
Digital processes & 0.857 & 0.902 & 0.698 \\
\hline
\end{tabular}


Table 4. Path coefficients, effect sizes, $p$ values, and $R^{2}$ in our model.

\begin{tabular}{|c|c|c|c|c|c|c|c|c|c|c|}
\hline \multirow{2}{*}{$\begin{array}{l}\text { Dependent variables } \\
\text { Independent variables }\end{array}$} & \multicolumn{2}{|c|}{$\begin{array}{c}\text { Digital IT } \\
\text { capabilities }\end{array}$} & \multicolumn{2}{|c|}{$\begin{array}{l}\text { Employees' } \\
\text { digital } \\
\text { capabilities }\end{array}$} & \multicolumn{2}{|c|}{ Digital culture } & \multicolumn{2}{|c|}{$\begin{array}{c}\text { Digital pro- } \\
\text { ducts/services } \\
\text { HXa } \\
\end{array}$} & \multicolumn{2}{|c|}{$\begin{array}{l}\text { Digital pro- } \\
\text { cesses } \mathrm{HXb}\end{array}$} \\
\hline & $\beta$ & $f_{2}$ & $\beta$ & $f_{2}$ & $\beta$ & $f^{2}$ & $\beta$ & $f_{2}$ & $\beta$ & $f^{2}$ \\
\hline H1: Digital strategy & $0.641^{* * *}$ & 0.689 & $0.638^{* * *}$ & 0.685 & $0.336^{* * *}$ & 0.128 & $0.360^{* * * *}$ & 0.140 & $0.244^{*}$ & 0.054 \\
\hline H2: IT capabilities & & & & & & & $0.286^{* *}$ & 0.091 & $0.367^{* * *}$ & 0.126 \\
\hline $\begin{array}{l}\text { H3: Employees' digital } \\
\text { capabilities }\end{array}$ & & & & & & & 0.100 & 0.010 & 0.010 & 0.000 \\
\hline H4: Digital culture & \multirow{2}{*}{\multicolumn{2}{|c|}{0.411}} & \multirow{2}{*}{\multicolumn{2}{|c|}{0.407}} & \multirow{2}{*}{\multicolumn{2}{|c|}{0.112}} & $0.153 \dagger$ & 0.035 & \multirow{2}{*}{\multicolumn{2}{|c|}{0.463}} \\
\hline & & & & & & & 0.55 & & & \\
\hline
\end{tabular}

Note. $\beta=$ coefficient, $f 2=$ effect size.

t $p<.10,{ }^{*} p<.05,{ }^{* *} p<.01,{ }^{* * *} p<.001$.

and H4b, but we must reject H3b. Furthermore, a high explained variance (above 45 percent) indicates that the degree of digital processes is well explained by digital strategy, digital IT capabilities, and digital culture. In addition, a digital strategy can explain the digital IT capabilities, as evidenced by a high value for the explained variance of 41.1 percent. However, the digital strategy does not explain the digital culture, as indicated by a low value for the explained variance of only 11.3 percent. Figure 2 summarizes our results.

With regard to the control variables, the age of the company as well as the investment round showed no significance, so we removed them from the model. Further, we extracted the latent variables scores of the constructs of the model. We used the scores to calculate a regression model with industry

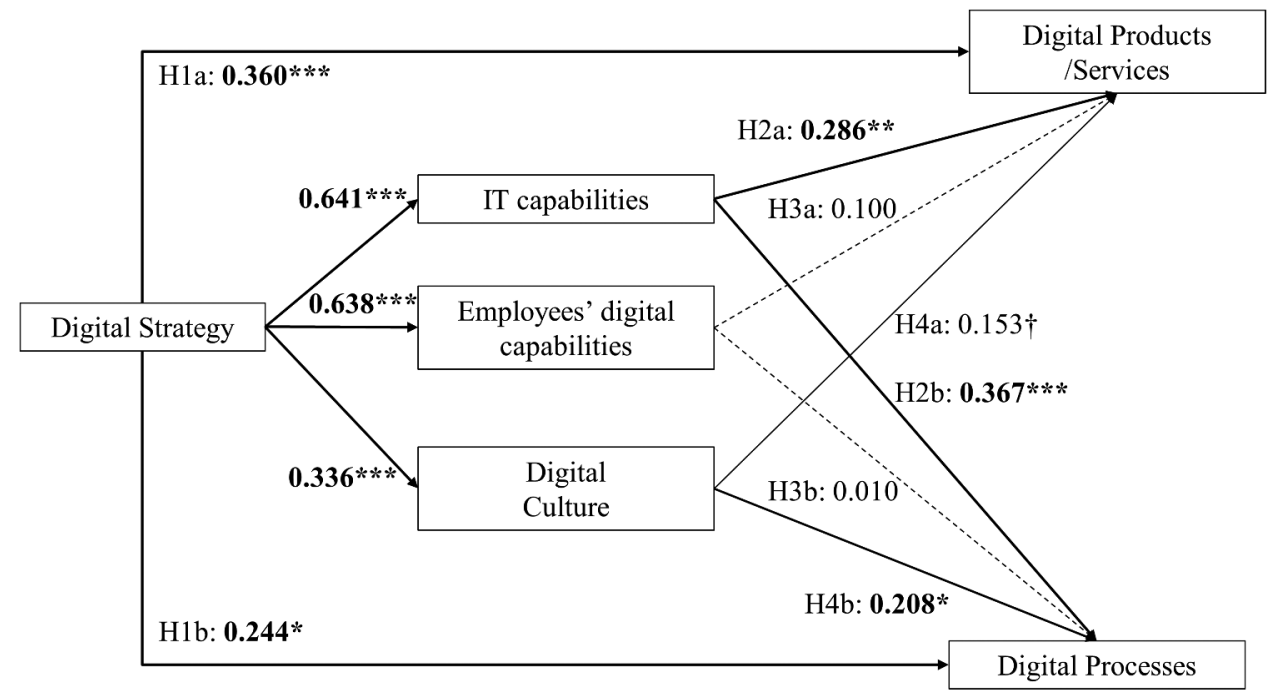

$$
\dagger p<0.10,{ }^{*} p<0.05,{ }^{* *} p<0.01,{ }^{* * *} p<0.001 .
$$

Figure 2. Graphical representation of path coefficients of the PLS model. 
dummies for each industry with more than seven mentions. For the construct digital products/services, none of the industry variables was significant. Although the industry dummy for "consumer service" was significant on a 95 percent level for the variable digital processes with a positive coefficient, only 11 of our 102 cases belong to the industry. The other coefficients changed only slightly, suggesting that no other industries had an influence on the degree of digital processes.

Moreover, we checked for possible multicollinearity among our independent constructs. The low values for the variance inflation factors (VIFs) indicate that this is not an issue in our model (see Online Appendix OA. C1). To test for a possible common method bias, we first referred to Kock's (2015) method, which states that a common method bias can be identified based on the VIFs of the constructs. He proposes regressing all constructs on a random variable and then calculating the resulting VIFs. He argues that the threshold for common method variance is a VIF higher than 3.3 (Kock, 2015; Kock \& Lynn, 2012). In our sample, all VIFs are below this value (see Online Appendix OA.C2). Furthermore, we followed Rönkkö and Ylitalo's (2011) maker variable approach, which involves adding a variable uncorrelated to the constructs of the model and then checking the average correlation with each item. The correlation will capture any common variance bias; if it is below 0.05 , no bias exists. We chose an item measuring whether less office space is needed due to the digitalization of the new venture. The average correlation with the items in our mode is 0.001 , confirming that our model does not exhibit common method bias.

Last, we controlled for possible endogeneity bias induced by reverse causality. In line with Hult et al. (2018), we first used the control variables as previously described. As we were unable to identify a potential bias with this method, we applied the Gaussian copula approach (Park \& Gupta, 2012). We first assessed the nonnormality of our four independent constructs by running the Kolmogorov-Smirnov test with Lilliefors correction to assess whether the Copula approach could be applied. All four independent variables are nonnormally distributed (see Online Appendix D). Then we recalculated the two models including the copulas of our four enabler constructs. We could not identify an endogeneity problem in the models as none of the copulas were significant. We therefore conclude that our data do not suffer from a reverse causality issue.

\section{Discussion}

Our findings provide broad support for our theoretical conceptualization on how a digital strategy enables a high degree of digitalization in new ventures in terms of digital products/services and digital processes. We looked at three mediators in this relationship: digital IT capabilities, employees' digital 
capabilities, and digital culture. Our results indicate that in particular the digital IT capabilities and the digital culture play a role.

Although the products and services offered by new ventures are mainly dependent on the founders of new ventures, our results show that the degree of the digitalization of the products/services offered is influenced by the digital strategy, which is most likely implemented by the founders as well. This finding is in line with previous research that highlights the importance of the founder in a new venture's success (Song et al., 2008). Having a digital product or service offered (for example, providing an e-commerce platform) also leads to higher average sales growth rates, which derives a competitive advantage for new ventures (Abebe, 2014). This finding can be explained by the fact that a high degree of digitalization enables a high scalability of the products and services offered as well as a rapid launch of new products and services. Moreno-Moya and Munuera-Aleman (2016) showed that the ladder has a positive performance impact in SMEs.

Our investigations show that the digital strategy has a direct relation to digital processes, but a much weaker one. Here we contradict the research in the SME context by Bi et al. (2019), who showed the importance of a critical role of top management in assimilating digital business within the organization, and S.H. Kim et al. (2017), who showed that management support is more important than IT capacity for the adaption of Software as a Service (SaaS) in SMEs. One explanation is that the founders tend to focus more on factors that are visible from outside and less on managing the internal processes, especially in the beginning. A reason might be that new ventures lack the resources to manage both. Although this approach might have its advantages in the early stages, it can be a challenge when the new venture experiences fast growth. It can lead to inefficiencies and reduce the productivity.

We identify digital IT capabilities as an important mediator of a high degree of digitalization in new German ventures. This result is in line with the research of Bi et al. (2019), who showed the influence of IT business spanning capability on competitive process alignment for SMEs. As new ventures often have limited resources, a lack of IT resources might be problematic and potentially hinder fast digitalization and therefore the scaling of the business. This is especially the case for the digitalization of processes: Digital IT capabilities strongly mediate them. Possibly, new digital ventures use their digital IT capabilities more on what is visible to investors and customers when IT resources are scare: the digitalization of the products. Furthermore, following the results of Mohd Salleh et al. (2017), the founders might not be fully aware of the benefits of process digitalization.

Employees' digital capabilities do not play a significant role as a mediator in our model. This marks a clear departure from findings in the corporate literature that highlight the need to develop employees' digital capabilities to successfully digitalize (Kane et al., 2017; Neus et al., 2017). New ventures tend 
to have better access to skilled employees due to the network and experience of their founders (Zahra \& George, 1999). Furthermore, Symeonidou and Nicolaou (2018) show that higher human capital investments compared with rivals do not necessarily lead to better company performance. The lack of a significant influence of employees' digital capabilities on digitalization in our model may also be explained by a self-selection bias. New ventures often employ relatively young people who are digital natives and therefore likely to use digital products/services. Alternatively, they may include digital competencies in their hiring criteria. The latter factor scored an average of 4 out of 5 in our survey, meaning on average they agree to that statement.

A digital culture is a further mediator for digital processes in new ventures, in line with current research (Brettel et al., 2015; El Sawy et al., 2016). When beginning to digitalize manual processes, some tolerance of failure is necessary. The employees must be amenable to change, as digitalization makes it necessary to do things in new ways. In addition, the management of new ventures might focus more on product/service digitalization as they must show results to financial investors. A working product might be more important in the beginning than running an efficient business. Possibly, the digitalization of processes might be triggered by the employees to make things easier for themselves-in a sense, making it an employee-driven innovation process (Kesting \& Ulhøi, 2010). Interestingly, digital culture cannot be explained by the digital strategy. A reason for that may be that new ventures often lack hierarchies in the beginning (Minguzzi \& Passaro, 2001). Rather than enforcing decisions from the top, employees freely work on different projects. The management sets the goals for the product or service development and digitalization but does not tell the employees how to do it. They do not "construct" the digital culture but rather let it unfold (Hayton \& Cacciotti, 2013).

\section{Implications}

From a theoretical perspective, our study delivers empirical evidence on the influence of a digital strategy on the degree of digitalization of products/ services and processes building on the contingence theory. We followed Ott et al.'s (2017) and García-Cabrera et al.'s (2019) calls for research to explicitly study the role of strategy in the entrepreneurial context as well as of Steiniger's (2019) to contribute to the research of combining digital technologies and entrepreneurship. Furthermore, we contribute to the discussion by Bi et al. (2019), Eggers et al. (2017), and Cragg et al. (2013) of the role of IT in small businesses. In addition, we contribute to the literature by highlighting the appropriateness of using the contingency theory for strategic issues in entrepreneurship (Gruber et al., 2010).

We emphasize the important role of a digital strategy in the digitalization of products/services. The results point to a similar direction like Tornikoski 
et al.'s (2017) idea of technological distinctiveness. In this regard, we further show how internal contingencies can result in organizational outcomes. We highlight that digital IT capabilities as well as a digital culture influence the degree of digitalization in terms of products/services and processes in new ventures, which is assigned a variety of benefits like rapid scaling or a higher flexibility. However, future research is needed to determine how the degree of digitalization affects new ventures' output and performance.

In addition, we showed the importance of IT capabilities for enabling digitalization. We currently lack the understanding of how digital IT capabilities for digital processes and digital products/services might differ and call for further research to understand this phenomenon better.

Furthermore, we found new results in the area of the roles of digital culture. Digital culture has an influence on the degree of process digitalization. Surprisingly, digital strategy does not explain digital culture well. Future research should attempt to explain this effect. Currently, only limited empirical research addresses digital culture, especially with respect to strategic issues.

Our work has several practical implications. First, we show that a digital strategy is influencing the degree of digitalization of new ventures' products and services. Thus, founders who wish to increase the degree of digitalization of products and services, for example, to increase the potential for rapid scaling, can focus on implementing a digital strategy in their new venture.

Second, we highlight that the effect of the digital strategy on the digitalization of processes is strongly mediated by the digital IT capabilities. These results can be used by founder-supported initiatives, such as accelerators, by offering services and infrastructure for faster digitalization of new ventures. Especially in the early phases, new ventures might not have the resources needed to establish a sophisticated IT infrastructure in a way that supports further digitalization. This result is also relevant for founders, who should adapt their strategy to use more resources on digital IT capabilities, as a high degree of digitalization in processes can lead to cost savings and greater efficiencies and might enable a rapid scaling of the venture.

Third, we show that the influence of digital strategy on digital processes is mediated by a digital culture. Increasing digitalization carries a risk of failure, especially considering that the solutions for some areas will be completely new. Therefore, a failure-tolerating culture-an element of the digital culture-can enhance digitalization. New ventures can actively engage in establishing such a culture.

\section{Limitations}

Our study has two main limitations that should be addressed in future research. First, we used entrepreneurs' self-assessments to study the degree of digitalization of new ventures, which could be positively biased. In other 
words, entrepreneurs might be more inclined to create a positive image of their venture, especially as a high degree of digitalization often has a positive connotation in the media. However, before distributing the survey, we clearly stated that the data would be kept anonymous, which should have reduced participants' motivation to exaggerate the degree of digitalization. In addition, we did not inform participants that we were studying the interconnections between enablers and the degree of digitalization.

Second, we focused on the digitalization of new ventures in Germany. Whether the results can be generalized to other countries, especially countries with a much higher or lower digitalization index, is unclear (see, for example, Chakravorti et al., 2017 for a cross-country comparison of digital competitiveness).

\section{References}

Abebe, M. (2014). Electronic commerce adoption, entrepreneurial orientation and small-and medium-sized enterprise (SME) performance. Journal of Small Business and Enterprise Development, 21(1), 100-116. https://doi.org/10.1108/JSBED-10-2013-0145

Amit, R., \& Zott, C. (2001). Value creation in e-business. Strategic Management Journal, 22 (6-7), 493-520. https://doi.org/10.1002/smj.187

Arkhipova, D., \& Bozzoli, C. (2018). Digital capabilities. In G. Bongiorno, D. Rizzo, \& G. Vaia (Eds.), CIOs and the digital transformation (pp. 121-146). Springer International Publishing AG.

Autio, E. (2017). Digitalisation, ecosystems, entrepreneurship and policy. Perspectives into topical issues in society and ways to support political decision making: Government's analysis, research and assessment. Activities Policy Brief.

BarNir, A., Gallaugher, J. M., \& Auger, P. (2003). Business process digitization, strategy, and the impact of firm age and size: The case of the magazine publishing industry. Journal of Business Venturing, 18(6), 789-814. https://doi.org/10.1016/S0883-9026(03)00030-2

Bassellier, G., Reich, B. H., \& Benbasat, I. (2001). Information technology competence of business managers: A definition and research model. Journal of Management Information Systems, 17(4), 159-182. https://doi.org/10.1080/07421222.2001.11045660

Bengtsson, M., Boter, H., \& Vanyushyn, V. (2007). Integrating the internet and marketing operations: A study of antecedents in firms of different size. International Small Business Journal, 25(1), 27-48. https://doi.org/10.1177/0266242607071780

Berger, E. S. C., Von Briel, F., Davidsson, P., \& Kuckertz, A. (2018). Digital or not - The future of entrepreneurship and innovation. Journal of Business Research. Call for Papers. https:// ent.aom.org/ent/events/eventdescription?CalendarEventKey=4605d1d8-4029-4ff8-88106cab9000a50b\&CommunityKey=fe00dbd4-230d-471e-a0ed-420a47166316

Berghaus, S., Back, A., \& Kaltenrieder, B. (2017). Digital maturity \& transformation report 2017. Crosswalk AG.

Bharadwaj, A., Sawy, O. A. E., Pavlou, P. A., \& Venkatraman, N. (2013). Digital business strategy: Toward a next generation of insights. MIS Quarterly, 37(2), 471-482. https://doi. org/10.25300/MISQ/2013/37:2.3

Bi, R., Davison, R., \& Smyrnios, K. (2019). The role of top management participation and IT capability in developing SMEs' competitive process capabilities. Journal of Small Business Management, 57(3), 1008-1026. https://doi.org/10.1111/jsbm.12380 
Bleicher, J., \& Stanley, H. (2019). Digitization as a catalyst for business model innovation a three-step approach to facilitating economic success. Journal of Business Management, 5(2), 62-71. http://www.theaspd.com/resources/jbm\%20v5-2-5.pdf

Bogner, E., Voelklein, T., Schroedel, O., \& Franke, J. (2016). Study based analysis on the current digitalization degree in the manufacturing industry in Germany. Procedia CIRP, 57, 14-19. https://doi.org/10.1016/j.procir.2016.11.004

Brettel, M., Chomik, C., \& Flatten, T. C. (2015). How organizational culture influences innovativeness, proactiveness, and risk-taking: Fostering entrepreneurial orientation in SMEs. Journal of Small Business Management, 53(4), 868-885. https://doi.org/10.1111/ jsbm. 12108

Candi, M., \& Saemundsson, R. (2008). 'Oil in water? Explaining differences in aesthetic design emphasis in new technology-based firms. Technovation, 28(7), 464-471. https://doi.org/10. 1016/j.technovation.2008.03.002

Cenamor, J., Parida, V., \& Wincent, J. (2019). How entrepreneurial SMES compete through digital platforms: The roles of digital platform capability, network capability and ambidexterity. Journal of Business Research, 100, 196-206. https://doi.org/10.1016/j. jbusres.2019.03.035

Chakravorti, B., Bhalla, A., \& Chaturvedi, R. (2017). 60 countries' digital competitiveness, indexed. Harvard Business Review. https://hbr.org/2017/07/60-countries-digital-competitive ness-indexed

Chen, Y., Tang, G., Jin, J., Xie, Q., \& Li, J. (2014). CEOs' transformational leadership and product innovation performance: The roles of corporate entrepreneurship and technology orientation. Journal of Product Innovation Management, 31(1), 2-17. https://doi.org/10. $1111 /$ jpim. 12188

Chen, Y., Wang, Y., Nevo, S., Benitez-Amado, J., \& Kou, G. (2015). IT capabilities and product innovation performance: The roles of corporate entrepreneurship and competitive intensity. Information Management, 52(6), 643-657. https://doi.org/10.1016/j.im.2015.05.003

Chirico, F., Sirmon, D. G., Sciascia, S., \& Mazzola, P. (2011). Resource orchestration in family firms: Investigating how entrepreneurial orientation, generational involvement, and participative strategy affect performance. Strategic Entrepreneurship Journal, 5(4), 307-326. https://doi.org/10.1002/sej.121

Cragg, P., Mills, A., \& Suraweera, T. (2013). The influence of IT management sophistication and IT support on IT success in small and medium-sized enterprises. Journal of Small Business Management, 51(4), 617-636. https://doi.org/10.1111/jsbm.12001

Davidsson, P., Baker, T., \& Senyard, J. M. (2017). A measure of entrepreneurial bricolage behavior. International Journal of Entrepreneurial Behavior Research, 23(1), 114-135. https://doi.org/10.1108/IJEBR-11-2015-0256

DeLone, W., Migliorati, D., \& Vaia, G. (2018). Digital IT governance. In G. Bongiorno, D. Rizzo, \& G. Vaia. (Eds.), CIOs and the digital transformation. A new leadership role (pp. 205-230). Springer.

Denner, M. S., Püschel, L. C., \& Röglinger, M. (2018). How to exploit the digitalization potential of business processes. Business Information Systems Engineering, 60(4), 331-349. https://doi.org/10.1007/s12599-017-0509-x

Deuze, M. (2006). Participation, remediation, bricolage: Considering principal components of a digital culture. The Information Society, 22(2), 63-75. https://doi.org/10.1080/ 01972240600567170

Duerr, S., Holotiuk, F., Wagner, H. T., Beimborn, D., \& Weitzel, T. (2018). 'What is digital organizational culture? Insights from exploratory case studies', Paper presented at the Hawaii international conference on system sciences, Hawaii, January. 
Eggers, F., Hatak, I., Kraus, S., \& Niemand, T. (2017). Technologies that support marketing and market development in SMES-Evidence from social networks. Journal of Small Business Management, 55(2), 270-302. https://doi.org/10.1111/jsbm.12313

El Sawy, O. A. (2003). The IS core IX: The 3 faces of information systems identity: Connection, immersion, and fusion. Communications of the AIS, 12(39), 588-598. https://doi.org/10. 17705/1CAIS.01239

El Sawy, O. A., Kræmmergaard, P., Amsinck, H., \& Vinther, A. L. (2016). How LEGO built the foundations and enterprise capabilities for digital leadership. MIS Quarterly Executive, 15(2), 141-166. https://aisel.aisnet.org/misqe/vol15/iss2/5/

Faul, F., Erdfelder, E., Buchner, A., \& Lang, A.-G. (2009). Statistical power analyses using $\mathrm{G}^{*}$ power 3.1: Tests for correlation and regression analyses. Behavior Research Methods, 41 (4), 1149-1160. https://doi.org/10.3758/BRM.41.4.1149

Fischer, E., \& Reuber, A. R. (2014). Online entrepreneurial communication: Mitigating uncertainty and increasing differentiation via twitter. Journal of Business Venturing, 29(4), 565-583. https://doi.org/10.1016/j.jbusvent.2014.02.004

García-Cabrera, A. M., García-Soto, M. G., \& Olivares-Mesa, A. (2019). Entrepreneurs' resources, technology strategy, and new technology-based firms' performance. Journal of Small Business Management, 57(4), 1506-1530. https://doi.org/10.1111/jsbm.12411

Gruber, M., Heinemann, F., Brettel, M., \& Hungeling, S. (2010). Configurations of resources and capabilities and their performance implications: An exploratory study on technology ventures. Strategic Management Journal, 31(12), 1337-1356. https://doi.org/10.1002/smj.865

Gruber, M., Kim, S. M., \& Brinckmann, J. (2015). What is an attractive business opportunity? An empirical study of opportunity evaluation decisions by technologists, managers, and entrepreneurs. Strategic Entrepreneurship Journal, 9(3), 205-225. https://doi.org/10.1002/ sej. 1196

Hair, J. F., Hult, G. T. M., Ringle, C. M., \& Sarstedt, M. (2016). A primer on partial least squares structural equation modeling (PLS-SEM). SAGE Publications.

Hair, J. F., Sarstedt, M., Pieper, T. M., \& Ringle, C. M. (2012a). The use of partial least squares structural equation modeling in strategic management research: A review of past practices and recommendations for future applications. Long Range Planning, 45(5-6), 320-340. https://doi.org/10.1016/j.lrp.2012.09.008

Hair, J. F., Sarstedt, M., Ringle, C. M., \& Mena, J. A. (2012b). An assessment of the use of partial least squares structural equation modeling in marketing research. Journal of the Academy of Marketing Science, 40(3), 414-433. https://doi.org/10.1007/s11747-011-0261-6

Hakala, H., \& Kohtamäki, M. (2011). Configurations of entrepreneurial-customer-and technology orientation: Differences in learning and performance of software companies. International Journal of Entrepreneurial Behavior Research, 17(1), 64-81. https://doi.org/ $10.1108 / 13552551111107516$

Hayes, A. F. (2017). Introduction to mediation, moderation, and conditional process analysis: A regression-based approach. Guilford Press.

Hayton, J. C., \& Cacciotti, G. (2013). Is there an entrepreneurial culture? A review of empirical research. Entrepreneurship Regional Development, 25(9-10), 708-731. https://doi.org/10. 1080/08985626.2013.862962

Henseler, J., Ringle, C. M., \& Sinkovics, R. R. (2009). The use of partial least squares path modeling in international marketing. In R. R. Sinkovics \& P. N. Ghauri (Eds.), New challenges to international marketing (pp. 277-319). Emerald Group Publishing Limited.

Hull, C., Hung, Y., Hair, N., Perotti, V., \& Demartino, R. (2007). Taking advantage of digital opportunities: A typology of digital entrepreneurship. International Journal of Networking and Virtual Organisations, 4(3), 290-303. https://doi.org/10.1504/IJNVO.2007.015166 
Hult, G. T. M., Hair, J. F., Proksch, D., Sarstedt, M., Pinkwart, A., \& Ringle, C. M. (2018). Addressing endogeneity in international marketing applications of partial least squares structural equation modeling. Journal of International Marketing, 26(3), 1-21. https://doi. org/10.1509/jim.17.0151

Iivari, M. M., Ahokanga, P., Komi, M., Tihinen, M., \& Valtanen, K. (2016). Toward ecosystemic business models in the context of industrial internet. Journal of Business Models, 4(2), 42-59. http://journalofbusinessmodels.com/vol-4-no-2-2016/vol-4-no-2-pp-42-59/

Im, S., \& Workman, J. P. (2004). Market orientation, creativity, and new product performance in high-technology firms. Journal of Marketing, 68(2), 114-132. https://doi.org/10.1509/ jmkg.68.2.114.27788

Kallinikos, J., Aaltonen, A., \& Marton, A. (2013). The ambivalent ontology of digital artifacts. MIS Quarterly, 37(2), 357-370. https://doi.org/10.25300/MISQ/2013/37.2.02

Kane, G. C., Palmer, D., Phillips, A. N., \& Kiron, D. (2017). Winning the digital war for talent. MIT Sloan Management Review, 58(2), 17-19. https://sloanreview.mit.edu/article/winningthe-digital-war-for-talent/

Kannan, P. K., \& Li, H. A. (2017). Digital marketing: A framework, review and research agenda. International Journal of Research in Marketing, 34(1), 22-45. https://doi.org/10.1016/j.ijres mar.2016.11.006

Kearney, A., Harrington, D., \& Kelliher, F. (2019). Strategizing in the micro firm: A 'strategy as practice' framework. Industry and Higher Education, 33(1), 6-17. https://doi.org/10.1177/ 0950422218816232

Kesting, P., \& Ulhøi, J. P. (2010). Employee-driven innovation: Extending the license to foster innovation. Management Decision, 48(1), 65-84. https://doi.org/10.1108/ 00251741011014463

Khelil, N. (2016). The many faces of entrepreneurial failure: Insights from an empirical taxonomy. Journal of Business Venturing, 31(1), 72-94. https://doi.org/10.1016/j.jbusvent. 2015.08.001

Kickul, J., \& Walters, J. (2002). Recognizing new opportunities and innovation. The role of strategic orientation and proactivity in internet. International Journal of Entrepreneural Behaviour and Research, 8(6), 292-308. https://doi.org/10.1108/13552550210448375

Kim, N., Im, S., \& Slater, S. F. (2013). Impact of knowledge type and strategic orientation on new product creativity and advantage in high-technology firms. Journal of Product Innovation Management, 30(1), 136-153. https://doi.org/10.1111/j.1540-5885.2012.00992.x

Kim, S. H., Jang, S. Y., \& Yang, K. H. (2017). Analysis of the determinants of software-as-aservice adoption in small businesses: Risks, benefits, and organizational and environmental factors. Journal of Small Business Management, 55(2), 303-325. https://doi.org/10.1111/ jsbm.12304

Knight, G. A., \& Cavusgil, S. T. (2004). Innovation, organizational capabilities, and the born-global firm. Journal of International Business Studies, 35(2), 124-141. https://oi.org/ 10.1057/palgrave.jibs.8400071

Kock, N. (2015). Common method bias in PLS-SEM: A full collinearity assessment approach. International Journal of e-Collaboration, 11(4), 1-10. https://doi.org/10.4018/ijec. 2015100101

Kock, N., \& Lynn, G. (2012). Lateral collinearity and misleading results in variance-based SEM: An illustration and recommendations. Journal of the Association for Information Systems, 13 (7), 546-580. https://doi.org/10.17705/1jais.00302

KPMG. (2018). Venture pulse Q1 2018 - Global analysis of venture funding. KPMG International Limited. Retrieved September 22, 2020, from https://assets.kpmg.com/con tent/dam/kpmg/xx/pdf/2018/04/kpmg-venture-pulse-q1-2018.pdf 
Kuckertz, A., \& Prochotta, A. (2018). What's hot in entrepreneurship research 2018? Hohenheim Entrepreneurship Research Brief, 4, 1-7. http://opus.uni-hohenheim.de/voll texte/2018/1462/pdf/2018_Kuckertz_Prochotta_HERB.pdf

Kuhn, K. M., \& Galloway, T. L. (2015). With a little help from my competitors: Peer networking among artisan entrepreneurs. Entrepreneurship Theory and Practice, 39(3), 571-600. https:// doi.org/10.1111/etap.12053

Lukas, B. A., Whitwell, G. J., \& Heide, J. B. (2013). Why do customers get more than they need? How organizational culture shapes product capability decisions. Journal of Marketing, 77(1), 1-12. https://doi.org/10.1509/jm.10.0182

Lyytinen, K., Yoo, Y., \& Boland Jr., R. J. (2016). Digital product innovation within four classes of innovation networks. Information Systems Journal, 26(1), 47-75. https://doi.org/10.1111/ isj. 12093

Markus, M. L., \& Loebbecke, C. (2013). Commoditized digital processes and business community platforms: New opportunities and challenges for digital business strategies. MIS Quarterly, 37(2), 649-653. https://www.jstor.org/stable/43825930

Marvel, M. R., \& Lumpkin, G. T. (2007). Technology entrepreneurs' human capital and its effects on innovation radicalness. Entrepreneurship Theory and Practice, 31(6), 807-828. https://doi.org/10.1111/j.1540-6520.2007.00209.x

McAdam, R., Moffett, S., Hazlett, S. A., \& Shevlin, M. (2010). Developing a model of innovation implementation for UK SMEs: A path analysis and explanatory case analysis. International Small Business Journal, 28(3), 195-214. https://doi.org/10.1177/0266242609360610

McConnell, J. (2015). The company cultures that help (or hinder) digital transformation. Harvard Business Review Digital Articles, 2-5. https://hbr.org/2015/08/the-company-cul tures-that-help-or-hinder-digital-transformation

Minguzzi, A., \& Passaro, R. (2001). The network of relationships between the economic environment and the entrepreneurial culture in small firms. Journal of Business Venturing, 16(2), 181-207. https://doi.org/10.1016/S0883-9026(99)00045-2

Mohd Salleh, N. A., Rohde, F., \& Green, P. (2017). Information systems enacted capabilities and their effects on SMEs' information systems adoption behavior. Journal of Small Business Management, 55(3), 332-364. https://doi.org/10.1111/jsbm.12226

Moreno-Moya, M., \& Munuera-Aleman, J. L. (2016). The differential effect of development speed and launching speed on new product performance: An analysis in SMEs. Journal of Small Business Management, 54(2), 750-770. https://doi.org/10.1111/jsbm.12170

Nambisan, S. (2017). Digital entrepreneurship: Toward a digital technology perspective of a digital culture. The Information Society, 22(2), 63-75. https://doi.org/10.1111/etap.12254

Neergaard, H. (2007). Sampling in entrepreneurial settings. In H. Neergaard \& J. P. Ulhøi (Eds.), Handbook of qualitative research methods in entrepreneurship (pp. 275-278). Edward Elgar Publishing.

Nestpick. (2017). Best cities for startup employees. Nestpick Global Services. Retrieved September 22, 2020, from https://www.nestpick.com/best-cities-for-startup-employees

Neus, A., Buder, F., \& Galdino, F. (2017). Are you too successful to digitalize? How to fight innovation blindness. Innovation Blindness, 9(1), 30-35. https://www.nim.org/en/publica tions/gfk-marketing-intelligence-review/all-issues/digital-transformation/are-you-too-suc cessful-digitalize-how-fight-innovation-blindness

Nguyen, T. H., Newby, M., \& Macaulay, M. J. (2015). Information technology adoption in small business: Confirmation of a proposed framework. Journal of Small Business Management, 53(1), 207-227. https://doi.org/10.1111/jsbm.12058

Nitzl, C., Roldan, J. L., \& Cepeda, G. (2016). Mediation analysis in partial least squares path modeling. Industrial Management \& Data Systems, 116(9), 1849-1864. https://doi.org/10. 1108/IMDS-07-2015-0302 
Nylen, D., \& Holmström, J. (2015). Digital innovation strategy: A framework for diagnosing and improving digital product and service innovation. Business Horizons, 58(1), 57-67. https://doi.org/10.1016/j.bushor.2014.09.001

Ott, T. E., Eisenhardt, K. M., \& Bingham, C. B. (2017). Strategy formation in entrepreneurial settings: Past insights and future directions. Strategic Entrepreneurship Journal, 11(3), 306-325. https://doi.org/10.1002/sej.1257

Parida, V., \& Örtqvist, D. (2015). Interactive effects of network capability, ICT capability, and financial slack on technology-based small firm innovation performance. Journal of Small Business Management, 53(1), 278-298. https://doi.org/10.1111/jsbm.12191

Parida, V., Sjödin, D. R., Lenka, S., \& Wincent, J. (2015). Developing global service innovation capabilities: How global manufacturers address the challenges of market heterogeneity. Research-Technology Management, 58(5), 35-44. https://doi.org/10.5437/ 08956308X5805360

Park, S., \& Gupta, S. (2012). Handling endogenous regressors by joint estimation using copulas. Marketing Science, 31(4), 567-586. https://doi.org/10.1287/mksc.1120.0718

Pergelova, A., Manolova, T., Simeonova-Ganeva, R., \& Yordanova, D. (2019). Democratizing entrepreneurship? Digital technologies and the internationalization of female-led SMEs. Journal of Small Business Management, 57(1), 14-39. https://doi.org/ $10.1111 /$ jsbm. 12494

Porter, M. E., \& Heppelmann, J. (2014). How smart, connected products are transforming competition. Harvard Business Review, 92(11), 64-88. https://hbr.org/2014/11/how-smartconnected-products-are-transforming-competition

Prokesch, S. (2017). Reinventing talent management: How GE uses analytics to guide a more digital, far-flung workforce. Harvard Business Review, 95(5), 54-55. https://scholar.harvard. edu/people_analytics/publications/task-now-just-perform-execute-and-let-market-makeits-own

Punnett, B. J., \& Ricks, D. (1990). International business. PWS-Kent.

Rachinger, M., Rauter, R., Müller, C., Vorraber, W., \& Schirgi, E. (2018). Digitalization and its influence on business model innovation. Journal of Manufacturing Technology Management, 30(8), 1143-1160. https://doi.org/10.1108/JMTM-01-2018-0020

Rindfleisch, A., \& Moorman, C. (2001). The acquisition and utilization of information in new product alliances: A strength-of-ties perspective. Journal of Marketing, 65(2), 1-18. https:// doi.org/10.1509/jmkg.65.2.1.18253

Ringle, C. M., Wende, S., \& Becker, J. M. (2015). SmartPLS 3. SmartPLS.

Ritter, T., \& Gemünden, H. G. (2004). The impact of a company's business strategy on its technological competence, network competence and innovation success. Journal of Business Research, 57(5), 548-556. https://doi.org/10.1016/S0148-2963(02)00320-X

Rönkkö, M., \& Ylitalo, J. (2011). PLS marker variable approach to diagnosing and controlling for method variance. ICIS 2011 Proceedings, 8, 1-16. https://aisel.aisnet.org/icis2011/pro ceedings/researchmethods/8/

Sarangee, K. R., \& Echambadi, R. (2014). Firm-specific determinants of product line technology strategies in high technology markets. Strategic Entrepreneurship Journal, 8(2), 149-166. https://doi.org/10.1002/sej.1164

Sarstedt, M., Hair, J. F., Ringle, C. M., Thiele, K. O., \& Gudergan, S. P. (2016). Estimation issues with PLS and CBSEM: Where the bias lies! Journal of Business Research, 69(10), 3998-4010. https://doi.org/10.1016/j.jbusres.2016.06.007

Schuler, R. S., \& Jackson, S. E. (1987). Linking competitive strategies with human resource management practices. Academy of Management Executive, 1(3), 207-219. https://doi.org/ 10.5465/ame.1987.4275740 
Sebastian, I. M., Ross, J. W., Beath, C., Mocker, M., Moloney, F. G., \& Fonstad, N. O. (2017). How big old companies navigate digital transformation. MIS Quarterly Executive, 16(3), 197-213. https://publikationen.reutlingen-university.de/frontdoor/index/index/docId/1501

Shepard, J. M., \& Hougland, J. G. (1978). Contingency theory: "Complex man" or "complex organization"? The Academy of Management Review, 3(3), 413-427. https://doi.org/10.5465/ amr.1978.4305714

Sirmon, D. G., Hitt, M. A., Ireland, R. D., \& Gilbert, B. A. (2010). Resource orchestration to create competitive advantage: Breadth, depth, and life cycle effects. Journal of Management, 37(5), 1390-1412. https://doi.org/10.1177/0149206310385695

Song, M., Podoynitsyna, K., Van Der Bij, H., \& Halman, J. I. (2008). Success factors in new ventures: A meta-analysis. Journal of Product Innovation Management, 25(1), 7-27. https:// doi.org/10.1111/j.1540-5885.2007.00280.x

Souza, C. A. D., Siqueira, É. S., \& Reinhard, N. (2017). Digital divide of small and medium-sized enterprises: An analysis of influencing factors using the toe theory. Mackenzie Management Review, 18(2), 15-48. https://doi.org/10.1590/1678-69712017/ administracao.v18n2p15-48

Srinivasan, R., Lilien, G., \& Rangaswamy, A. (2002). Technological opportunism and radical technology adoption: An application to e-business. Journal of Marketing, 66(3), 47-60. https://doi.org/10.1509/jmkg.66.3.47.18508

Startup Genome. (2017). Global Startup Ecosystem Report 2017. Retrieved September 22, 2020, from https://startupgenome.com/report2017/

Steininger, D. M. (2019). Linking information systems and entrepreneurship: A review and agenda for IT-associated and digital entrepreneurship research. Information Systems Journal, 29(2), 363-407. https://doi.org/10.1111/isj.12206

Symeonidou, N., \& Nicolaou, N. (2018). Resource orchestration in start-ups: Synchronizing human capital investment, leveraging strategy, and founder start-up experience. Strategic Entrepreneurship Journal, 12(2), 194-218. https://doi.org/10.1002/sej.1269

Tang, J., \& Murphy, P. J. (2012). Prior knowledge and new product and service introductions by entrepreneurial firms: The mediating role of technological innovation. Journal of Small Business Management, 50(1), 41-62. https://doi.org/10.1111/j.1540-627X.2011.00343.x

Teece, D. J. (2007). Explicating dynamic capabilities: The nature and microfoundations of (sustainable) enterprise performance. Strategic Management Journal, 28(13), 1319-1350. https://doi.org/10.1002/smj.640

Tornikoski, E. T., Rannikko, H., \& Heimonen, T. P. (2017). Technology-based competitive advantages of young entrepreneurial firms: Conceptual development and empirical exploration. Journal of Small Business Management, 55(2), 200-215. https://doi.org/10.1111/jsbm. 12315

Venkatraman, N., \& Camillus, J. C. (1984). Exploring the concept of 'fit' in strategic management. Academy of Management Review, 9(3), 513-525. https://doi.org/10.5465/amr.1984. 4279696

Von Briel, F., Davidsson, P., \& Recker, J. (2018). Digital technologies as external enablers of new venture creation in the IT hardware sector. Entrepreneurship Theory and Practice, 42(1), 47-69. https://doi.org/10.1177/1042258717732779

Wales, W. J., Patel, P. C., Parida, V., \& Kreiser, P. M. (2013). Nonlinear effects of entrepreneurial orientation on small firm performance: The moderating role of resource orchestration capabilities. Strategic Entrepreneurship Journal, 7(2), 93-121. https://doi.org/10.1002/ sej.1153

Zahra, S. A. (1995). Corporate entrepreneurship and financial performance: The case of management leveraged buyouts. Journal of Business Venturing, 10(3), 225-247. https://doi. org/10.1016/0883-9026(94)00024-O 
Zahra, S. A., \& George, G. (1999). Manufacturing strategy and new venture performance: A comparison of independent and corporate ventures in the biotechnology industry. Journal of High Technology Management Research, 10(2), 313-345. https://doi.org/10.1016/S10478310(99)00012-7

Zhou, K. Z., Yim, C. K., \& Tse, D. K. (2005). The effects of strategic orientations on technologyand market-based breakthrough innovations. Journal of Marketing, 69(2), 42-60. https://doi. org/10.1509/jmkg.69.2.42.60756 